\title{
The potential of a multi-mode data collection design to reduce non response bias. The case of a survey of employers
}

\author{
Emanuela Sala • Peter Lynn
}

Published online: 24 November 2007

(C) Springer Science+Business Media B.V. 2007

\begin{abstract}
The aim of the paper is to compare two alternative survey designs in terms of resultant response rates, non response bias and cost. The first design is a simple postal survey with follow-up mailings; the second design is a two-phase multi-mode design, where the postal survey is followed at the second phase by a telephone survey of non-respondents. We present a case study based on a survey of employers. In this study we find evidence that the sample obtained using only postal methods is biased in important respects. Bias is not apparent in the demographic characteristics of the employees. But bias is observed in some of the employees' employment characteristics and some of the characteristics of the firms in which they work. The multi mode design seems, overall, to have reduced or removed the bias of the postal sample. Only in marginal respects was some further bias introduced. We also compare costs of the two designs, to enable a comparison of cost-effectiveness at bias reduction.
\end{abstract}

Keywords Postal survey $\cdot$ Survey costs $\cdot$ Survey design $\cdot$ Telephone survey $\cdot$ Response rates $\cdot$ Non response bias $\cdot$ Multi mode

\section{Introduction}

Survey designers as well as researchers are increasingly concerned about the general trend towards increased non response rate in surveys (Dillman and Carley-Baxter 2000; de Heer 1999; Steeh et al. 2001). As put by Luo and White, "obtaining higher response rates in surveys is becoming increasingly difficult. This is happening in both household and establishment surveys" (2005, p. 3915). Scholars have therefore addressed their attention to how to encourage response and reduce response burden. Research on such topics has consistently found

E. Sala $(\varangle) \cdot$ P. Lynn

Institute for Social and Economic Research, University of Essex, Colchester,

Essex CO4 3SQ, UK

e-mail: esala@essex.ac.uk 
that multi mode survey designs are an effective means to increase response rates, particularly in the case of surveys of individuals and households (see, for example, de Leeuw 2005; Gallagher et al. 2005).

However, few studies have assessed whether any benefit of multi mode data collection in terms of response rate carries through into an improvement in terms of non-response bias. And most of the multi mode studies in the literature are based on surveys of households or individuals within households, rather than establishments. This article makes two main contributions to the literature: a direct assessment of the effect of multi mode data collection on non-response bias, and an example of the applicability of the approach in a situation other than a household survey.

Establishment surveys have to deal with methodological issues that are quite different from the ones researchers normally face while carrying out other kinds of surveys. The process of making contact and obtaining co-operation, for example, is usually longer and more complicated, while the dynamics of the response process are specific to this kind of survey (Paxson et al. 1995). Additionally, in many_perhaps most—countries a large proportion of establishment surveys are carried out by National (or Regional) Statistical Institutes (Cox et al. 1995). These surveys typically have long-established processes, participation is compulsory, and they are viewed as administrative routines rather than surveys (Smith et al. 2003; Luo and White 2005). It is no surprise, therefore, that the response rates obtained for business surveys carried out by National Statistical Institutes are usually quite high and usually higher than the ones obtained for business surveys carried out by academics. Willimack et al., for example, report that the unweighted unit response rates for surveys sponsored by U.S. government statistical agencies range from $60 \%$ to over $90 \%$ (2002, p. 215).

In spite of the high response rates, researchers seem to be increasingly concerned that the general trend towards increased non response in surveys might affect also business surveys. There has been an upsurge in research into methods to increase response rates (Fisher et al. 2003; Fox et al. 2003; Haraldsen 2004; Kaplan and Whiter 2002; Petroni et al. 2004; Tarnai and Paxson 2004), though little or no explicit consideration of non response bias is evident. The main reason why researchers should be concerned about non response is the potential for it to introduce bias. We are not aware of many studies that focus on the relationship between response rates and non response bias in the case of business surveys (cf. Groves 2006; Keeter et al. 2000; Curtin et al. 2000 in the case of household surveys). Even less is known about the effects of multi-mode data collection strategies on non-response bias in the case of business surveys.

The ultimate aim of our paper is to describe the effects of multiple phases of data collection, using different modes, on response rates and non response bias. In particular, we assess the relative cost-effectiveness of two alternative survey designs at minimising non-response bias on a business survey.

The paper is divided into 6 sections. We begin by describing the methodological context for the employer survey upon which our study is based (Sect. 2), then we look at the response rates obtained at the two stages of the survey (a postal stage and a telephone stage) and we discuss reasons for refusal (Sect. 3). We then compare the two designs in terms of non-response bias (Sect. 4) and data collection costs (Sect. 5). Finally we give an overall evaluation of the two stage (postal and telephone) design adopted, compared with a simple one stage postal survey with respect to non-response bias and costs (Sect. 6). 


\section{Case study: survey of employers}

The employer survey upon which this paper is based is part of a large-scale methodological project known as ISMIE, Improving Survey Measurement of Income and Employment. ${ }^{1}$ In the context of this project, a validation study was carried out. The aim was to validate data about employment conditions collected in a face-to-face household interview survey, the ISMIE survey. The validation data were to be collected by means of a subsequent survey of the employers of the persons interviewed in the household survey. It is this survey of employers that forms the basis of our study.

\subsection{The ISMIE survey}

The ISMIE sample consists of the 'low income' subsample of the UK part of the European Community Household Panel (ECHP) Study. All members of this sample who were successfully interviewed during the final (2001) wave of the BHPS-ECHP panel (1,163 individuals) were included in the ISMIE survey and interviews were completed with 1,033 of them. The sample is not fully representative of the UK household population both due to the selective nature of the sample and due to subsequent attrition. However, this is not detrimental to the current study as non-response is assessed by reference to the issued sample, not to the population. The characteristics of the ISMIE sample are nevertheless broadly similar to those of the total UK population on several demographic dimensions (Jäckle et al. 2004).

During the ISMIE survey detailed information about the employment situation of the respondents was collected. In particular respondents were asked for information about their employer (industry, workplace size), their job characteristics (occupation, employee/selfemployed, managerial duties, usual working hours, working hours arrangements) and their income (last gross/net pay, hourly rates of pay, rates for overtime, availability and membership of pension schemes). The data collection took place in spring 2003.

During the interview, members of the ISMIE sample who were currently in employment (excluding the self-employed) were asked for written permission to approach their employer to request some further details of their employment (Jenkins et al. 2006). If permission was given, they were then asked to provide contact information for their employer. The contact information requested included the name of a person within the employing organisation who would know about the nature of the ISMIE respondent's employment and pay. The names and contact details of employers provided by the ISMIE respondents constituted the sample for the consequent employer survey.

\subsection{The employer survey}

The employer survey was designed as a multi mode survey, with a postal stage followed by a telephone follow up of non-respondents. ${ }^{2}$ At the postal stage, questionnaires were mailed to the person who had been named by the ISMIE respondent. In a few cases where no name was provided, the questionnaire was addressed to "Human Resources". Following the initial mailing, there were two stages of reminder mailings; the first consisted of a letter and the second a re-administration of the questionnaire. At the phone stage of the survey calls

\footnotetext{
${ }^{1}$ For a detailed description of the aims, the research design and the methodology of the ISMIE project, see Jäckle et al. (2004). Findings from the ISMIE project are published in Lynn and Sala (2004, 2006), Lynn et al. (2004, 2006), Jäckle and Lynn (in press), Jenkins et al. (2006, in press).

${ }^{2}$ For a description of the employer survey, in particular with regard to the contact and response process, see Lynn and Sala $(2004,2006)$.
} 
were made to the phone numbers indicated by the ISMIE respondents. If no information was provided or if the phone numbers were incomplete or incorrect, telephone numbers were sought in the Internet websites of Yellow Pages and British Telecom and via internet search engines. The telephone calls aimed to encourage the employer to return the postal questionnaire or to answer the questions as a telephone interview. The employer survey was carried out between July 2003 and January 2004. The final response rate obtained for the employer survey was $72 \%$.

The questionnaire that was used for the employer survey contained a subset of the questions that had been asked to the respondents in the ISMIE survey regarding their own employment situation.

\section{The response process}

In this section we examine the response rates obtained with the two different survey designs and we discuss the reasons for refusal. Of the 1,033 respondents to the ISMIE survey, 434 were employees, $59 \%$ of whom (254) consented to take part in the employer survey. One of the consenting employees did not provide any contact information for his employer, therefore the eligible sample consists of 253 employers.

The response status and the response rates for the employer survey are shown in Table 1. The response rate and the explicit refusal rate obtained with the postal survey design are respectively $51 \%$ and $13 \%$. It is of course impossible to know with a postal survey what proportion of the remaining $36 \%$ are non-contacts (i.e. the addressee or target respondent never received the questionnaire) and what proportion are refusals (the addressee or target respondent chose not to return it). The 91 employers from whom no reply was received at the postal stage of the survey were then contacted by telephone. The response rate for the telephone stage (conditional upon having not responded to the postal stage) is $57 \%$ while the refusal rate is $37 \%$.

The total response rate obtained is therefore $72 \%$, with a refusal rate of $27 \%$ and a noncontact rate of $2 \%$. This response rate compares favourably with many academic household

Table 1 Response status and response rates for employer survey by survey designs (numbers and rates)

\begin{tabular}{lccc}
\hline Response status & \multicolumn{2}{l}{ Survey design } & \\
\cline { 2 - 4 } & Postal survey & $\begin{array}{l}\text { Telephone } \\
\text { follow up }\end{array}$ & $\begin{array}{l}\text { Multi mode } \\
\text { design }\end{array}$ \\
\hline Numbers & 129 & 52 & 181 \\
Questionnaires & & & \\
$\quad$ completed & 33 & 34 & 67 \\
Refused & 91 & - & - \\
No reply & - & 5 & 5 \\
Non-contact & 253 & 91 & 253 \\
Total eligible & & & \\
Percentages & 51.0 & 57.1 & 71.5 \\
Response rate & 13.0 & 37.4 & 26.5 \\
Refusal rate & - & 5.5 & 2.0 \\
Non-contact rate & & & \\
\hline
\end{tabular}


Table 2 Reasons for refusals by survey designs (numbers)

\begin{tabular}{lrr}
\hline & $\begin{array}{r}\text { Postal } \\
\text { design }\end{array}$ & $\begin{array}{r}\text { Telephone } \\
\text { followup }\end{array}$ \\
\hline $\begin{array}{l}\text { General refusal/no specific reasons } \\
\text { Company policy and confidentiality } \\
\quad \text { issues }\end{array}$ & 9 & 11 \\
$\begin{array}{l}\text { Issues related to the employees } \\
\quad \text { no permission from employees, } \\
\text { employees unknown) }\end{array}$ & 10 & 13 \\
$\begin{array}{l}\text { Issues related to the employers } \\
\text { (no time, no incentives) }\end{array}$ & 4 & 5 \\
$\begin{array}{l}\text { Others } \\
\text { Total = All explicit refusals }\end{array}$ & - & 3 \\
\hline
\end{tabular}

surveys and with the (American) academic surveys of establishments reported in Dillman (2000, p. 331), and Paxson et al. (1995, pp. 307-308).

Some indication of the reasons for refusal is presented in Table 2. It should be noted that during the postal stage, these reasons were not collected in a systematic way. However, 33 employers communicated their reasons and we have coded those reasons to the categories presented in Table 2. During the telephone stage, reasons were requested and recorded systematically. Despite this caveat, and the small sample sizes involved, some indication of the causes of refusal emerges. Four main types of refusals are identified: issues related to the employees (difficulties in chasing up/checking consent with the employees; problems in checking the records of the employees), issues related to the employers (no time, lack of motivation), company policies in relation to confidential matters, and general or non-specific refusals. Company policy issues appear less prevalent at the telephone stage. This may be because most companies where this applies had already refused at the postal stage and therefore did not enter the telephone stage. However, it could also be the case that concerns of the employers in relation to confidentiality were easier to overcome in the telephone mode.

\section{Non-response bias}

In this section we investigate non-response bias. We treat the data collected during the ISMIE survey as the eligible sample (the eligible sample consists of the 253 respondents who gave permission to contact their employers and who provided employer contact details) and compare the employer survey responding sample under alternative designs to assess non response bias. We compare the structure of the responding samples obtained using a one mode (postal) design and a multi mode (postal plus telephone) design with the complete (attempted) sample. We aim to check if the sample obtained with the first design is biased and if the sample obtained with the multimode design reduces such bias.

\subsection{Sample composition at the different stages of the data collection process}

We assess non-response bias in terms of three sets of variables: demographic characteristics of the employees (sex, age and ethnicity), employment characteristics of the employees (whether the employees have managerial duties, weekly gross pay, weekly hours of work (including overtime), whether the respondents work overtime and type of occupation) and 
Table 3 Sample composition by demographic variables of the employees (column percentages)

\begin{tabular}{|c|c|c|c|}
\hline & Postal design & Multi mode design & Total \\
\hline \multicolumn{4}{|l|}{ Sex } \\
\hline Male & 37.2 & 44.2 & 41.9 \\
\hline Female & 62.8 & 55.8 & 58.1 \\
\hline \multicolumn{4}{|l|}{ Age } \\
\hline $18-35$ & 30.2 & 32.0 & 32.0 \\
\hline $36-45$ & 35.7 & 35.4 & 36.0 \\
\hline 46 and over & 34.1 & 32.6 & 32.0 \\
\hline \multicolumn{4}{|l|}{ Ethnicity } \\
\hline White & 96.9 & 97.2 & 96.4 \\
\hline Others & 3.1 & 2.8 & 3.6 \\
\hline Base & 129 & 181 & 253 \\
\hline
\end{tabular}

characteristics of the firm in which the employees work (size of the firm, sector, location of the firm).

Table 3 shows the composition of the sample with respect to the demographic variables sex, age and ethnicity of the employees. The data show that under either survey design there is no evidence of non-response bias in respect of these variables.

The composition of the sample according to the employees' employment characteristics is shown in Table 4. The variables that we consider are: the employee's managerial duties, the gross pay per week, the total weekly hours of work, overtime work, and type of occupation (respondent's occupation is classified according to the Standard Occupational Classification, SOC) (Employment Department Group and Office of Population Censuses and Surveys 1990). The sample of employers responding to the postal survey looks biased with respect to managerial duties and type of occupation of the employees. Employees with managerial duties $(p=0.005)$ and employees with clerical and secretarial occupations $(p=0.007)$ tend to be overrepresented in the sample obtained with the postal design. The sample obtained with the multimode design reduces the bias in managerial duties $(p=0.020)$ and in the distribution of occupations. It removes, in particular, the overrepresentation of clerical and secretarial occupations though it slightly worsens the proportions of manager and administrators ( $p=0.017)$ and of "other occupations" ( $p=0.006)$. In these two last cases, the change in the statistical significance of the tests is due to both changes in the composition and in the numbers of the non respondent sample. The multimode design also seems to introduce some bias in the gross pay distribution. Employees who earn from 241 to 350 pounds a week $(p=0.011)$ are more likely to be present in the sample obtained with the multi mode design.

In Table 5 we look at the pattern of response from a different perspective. We examine the composition of the sample with respect to the characteristics of the firm in which the employees work: number of employees, industry sector (as measured by the Standard Industrial Classification (SIC) (Central Statistical Office 1992)) and location of the firm. 
Table 4 Sample composition by employees' employment characteristics (column percentages)

\begin{tabular}{|c|c|c|c|}
\hline & Postal design & Multi mode design & Total \\
\hline \multicolumn{4}{|l|}{ Managerial duties } \\
\hline Manager & $19.4^{* *}$ & $16.6^{*}$ & 13.4 \\
\hline Foreman/supervisor & 12.4 & 13.3 & 14.2 \\
\hline Not manager/supervisor & 68.2 & 70.2 & 72.3 \\
\hline Total & 129 & 181 & 235 \\
\hline \multicolumn{4}{|l|}{ Gross pay per week (pounds) } \\
\hline Less than 149 & 24.4 & 22.9 & 25.7 \\
\hline $150-240$ & 25.2 & 24.0 & 24.5 \\
\hline $241-350$ & 26.8 & $31.4^{*}$ & 27.0 \\
\hline 351 and more & 23.6 & 21.7 & 22.8 \\
\hline Total & 127 & 175 & 241 \\
\hline \multicolumn{4}{|l|}{ Total weekly hours of work (inc. overtime) } \\
\hline Less than 26 & 24.0 & 22.1 & 23.8 \\
\hline $27-36$ & 21.7 & 19.9 & 19.8 \\
\hline $37-41$ & 31.8 & 30.9 & 29.8 \\
\hline 42 and more & 22.5 & 27.1 & 26.6 \\
\hline Total & 129 & 181 & 252 \\
\hline \multicolumn{4}{|l|}{ Overtime work } \\
\hline No & 65.1 & 61.3 & 60.1 \\
\hline Yes & 34.9 & 38.7 & 39.9 \\
\hline Total & 129 & 181 & 253 \\
\hline \multicolumn{4}{|l|}{ Standard occupational classification } \\
\hline Managers \&administrators & 10.2 & $10.6^{*}$ & 8.0 \\
\hline Professional occupations & 4.7 & 3.9 & 4.4 \\
\hline Associate professional \& technical occupations & 10.2 & 8.4 & 8.4 \\
\hline Clerical \& secretarial occupations & $23.6^{* *}$ & 18.4 & 17.3 \\
\hline Craft \& related occupations & 9.4 & 10.6 & 9.2 \\
\hline Personal \& protective service occupations & 18.1 & 18.4 & 20.1 \\
\hline Sales occupations & 7.1 & 10.1 & 10.0 \\
\hline Plant \& machine operatives & 8.7 & 11.7 & 11.2 \\
\hline Other occupations & 7.9 & $7.8^{* *}$ & 11.2 \\
\hline Total & 127 & 179 & 249 \\
\hline
\end{tabular}

Note: For each category of each variable, in each design a chi-square test was carried out on the $2 \times 2$ table in which one axis is defined by the category contrasted with all other categories and the other by a dichotomous indicator of response. ${ }^{*} 0.05 \geq p>0.01 ;{ }^{* *} 0.01 \geq p>0.001$

The sample obtained with the postal design seems biased with respect to the sector and the location of the firm in which the employees work. Public sector firms are more likely than private sector firms to respond to the postal survey. Firms belonging to the public administration and education sector $(p=0.005)$ and firms located in the South West of England ( $p=0.044$ ) are more likely to be over represented while firms belonging to the wholesale and retail trade sector or to the hotel and restaurant sector $(p=0.017)$ or firms located in the West Midlands $(p=0.002)$ are more likely to be underrepresented. The multi mode design 
Table 5 Sample composition by firm characteristics (column percentages)

\begin{tabular}{|c|c|c|c|}
\hline & Postal design & Multi mode design & Total \\
\hline \multicolumn{4}{|l|}{ Size of the firm } \\
\hline Less than 24 employees & 30.2 & $27.1^{* *}$ & 32.0 \\
\hline 25-99 Employees & 27.1 & 29.3 & 27.7 \\
\hline 100 and more employees & 42.6 & 43.6 & 40.3 \\
\hline \multicolumn{4}{|c|}{ Standard industrial classification (SIC) } \\
\hline $\mathrm{A}, \mathrm{C}$ & 1.7 & 1.8 & 1.7 \\
\hline $\mathrm{D}, \mathrm{F}, \mathrm{I}$ & 22.5 & 23.2 & 24.1 \\
\hline $\mathrm{G}, \mathrm{H}$ & $17.5^{*}$ & 23.2 & 24.1 \\
\hline $\mathrm{J}, \mathrm{K}$ & 11.7 & 14.3 & 12.2 \\
\hline $\mathrm{L}, \mathrm{M}$ & $21.7^{* *}$ & 16.7 & 15.2 \\
\hline $\mathrm{N}, \mathrm{O}$ & 24.2 & 20.2 & 21.5 \\
\hline $\mathrm{P}$ & .8 & .6 & 1.3 \\
\hline \multicolumn{4}{|l|}{ Sector } \\
\hline Public & $45.8^{* *}$ & 36.9 & 36.7 \\
\hline Private & $54.2^{* *}$ & 63.1 & 63.3 \\
\hline \multicolumn{4}{|l|}{ Location of the firm } \\
\hline London and South East & 25.0 & 24.4 & 23.0 \\
\hline South West & $16.4^{*}$ & 14.4 & 12.3 \\
\hline East Anglia, East Midlands & 11.7 & $11.7^{*}$ & 15.1 \\
\hline West Midlands & $5.5^{* *}$ & 9.4 & 11.5 \\
\hline North & 25.0 & 23.3 & 22.6 \\
\hline Wales & 3.9 & 3.3 & 3.6 \\
\hline Scotland & 12.5 & 13.3 & 11.9 \\
\hline Base & 129 & 181 & 253 \\
\hline
\end{tabular}

Notes: Due to item non response, the base in some cases is smaller. SIC sections: A: Agriculture, hunting and forestry; C: Mining and quarrying; D: Manufacturing; E: Electricity, gas and water supply; F: Construction; G: Wholesale and retail trade; H: Hotels and restaurants; I: Transport, storage and communication; J: Financial intermediation; K: Real estate, renting and business activities; L: Public administration and defence; M: Education; N: Health and social work; O: Other community, social and personal service activities, P: Private households with employed persons. For each category of each variable, in each design a chi-square test was carried out on the $2 \times 2$ table in which one axis is defined by the category contrasted with all other categories and the other by a dichotomous indicator of response. ${ }^{*} 0.05 \geq p>0.01 ;{ }^{* *} 0.01 \geq p>0.001$

removes the bias associated with sector and with SIC distribution. Overall, it also reduces the bias in the distribution of the location of the firm. ${ }^{3}$ Furthermore, the multimode design introduces some bias in the distribution of the size of the firm. Small firms are less likely to be represented than in the total sample.

To sum up, the analyses carried out so far have shown that the sample obtained at the postal stage of the data collection seems to be biased in important respects. Bias is not apparent in the demographic characteristics of the employees. But bias is observed in some of the employees' employment characteristics and some of the characteristics of the firms in which they work. The multi mode design seems, overall, to have reduced or removed the bias of the

3 The change in significance of the estimate of firms located in East Anglia and East Midlands is entirely due to the change in the size of the responding sample. 
postal sample. Only in marginal respects was some further bias introduced by the telephone phase.

\subsection{Logit models of response propensity}

The limitation of the analyses that we have just described is that they do not take into account the relationships between the variables. In order to disentangle the role played by each single variable in the analysis of non response bias, net of the effects of the others, we developed two different logit models. The first one models the probability of response for the single mode design, the second one models the probability of response for the multi mode design. The results of the regressions are summarised in Table 6.

Table 6 Odds ratios from logistic regression

Independent variables

Demographic characteristics

Sex (baseline: male)

Female

Age (baseline: 18-35)

36-45

46 and over

Not manager/supervisor

Gross pay per week (baseline: less than $£ 149$ )

$£ 150-240$

0.942

$£ 241-350$

0.734

0.665

2.392

$£ 351$ and more

Total weekly hours of work (normal plus overtime)

(baseline: less than 26)

27-36

0.796

0.529

42 and more

0.639

Yes

Managers \& administrators

0.575

0.930

Professional occupations

0.333

1.314

Associate professional \& technical occupations

0.750

4.652

Craft \& related occupations

$0.263^{*}$

0.669

Sales occupations 
Table 6 continued

Independent variables

Plant \& machine operatives

Other occupations

Firm characteristics

Size of firm (baseline: less than 24 employees)

25-99 Employees

1.063

$3.426^{*}$

100 And more employees

1.136

Standard industrial classification (baseline: L, M)
A, C
D, F, I
G, H
$\mathrm{J}, \mathrm{K}$
$\mathrm{N}, \mathrm{O}$
$\mathrm{P}$

Location of the firm (baseline: West Midlands)

London and South East

0.608

0.360

0.911

$0.171^{* *}$

$0.195^{*}$

$0.273^{*}$

0.393

0.524

1.293

0.163

0.607

0.070

South West

3.229

1.714

4. $162^{*}$

2.594

East Anglia, East Midlands

North

1.608

0.580

3.264*

1.517

Wales

2.332

0.690

Scotland

3.790*

2.096

Pseudo $R^{2}$

0.152

0.195

Note: SIC sections: A: Agriculture, hunting and forestry; C: Mining and quarrying; D: Manufacturing; E: Electricity, gas and water supply; F: Construction; G: Wholesale and retail trade; H: Hotels and restaurants; I: Transport, storage and communication; J: Financial intermediation; K: Real estate, renting and business activities; L: Public administration and defence; M: Education; N: Health and social work; O: Other community, social and personal service activities; P: Private households with employed persons. ${ }^{*} 0.05 \geq p>0.01$; $* * 0.01 \geq p>0.001$

When we focus on the postal design, we find support for the results of the bivariate analyses of non response described in the previous section. There are, in particular, three features that stand out very clearly. The sample obtained with the postal design does not appear biased with respect to the demographic characteristics of the employees. The postal sample is biased with respect to some of the employees' employment characteristics, in particular with respect to managerial duties and, even if to a lesser extent, to the type of occupation of the employees. Other things being equal, the odds of employees who are not a manager or supervisor being represented in the postal sample are about $20 \%$ those of employees with managerial duties. Compared to employees in clerical and secretarial occupations, employees who have occupations related to personal and protective service or who have "other" types of occupations have odds ratios of about $1 / 4$ of being present in the postal sample. Moreover, the characteristics of the respondent sample differ significantly from those of the non respondent sample with respect to the sector and to the location of the firm. Ceteris paribus, firms that belong to the wholesale and retail trade sector and to the hotel and restaurants sector are less 
likely to answer the postal questionnaire than firms in the public administration, defence and education sectors (odds ratio 0.17). Firms involved in financial intermediation, real estate, renting and business activities are also less likely to respond to the postal survey than firms in the public administration, defence and education sectors (odds ratio 0.27). Firms located in the South West, in the North and in Scotland have much higher odds than firms located in the West Midlands to be represented in the postal survey sample.

With the multi mode data collection design, there is a much weaker association of the odds of responding with the covariates examined here. There is again no evidence of differential response with respect to the demographic characteristics of the respondents. Moreover, the multi mode design has removed the bias associated with the employment characteristics present in the first stage of the data collection process (managerial duties, SOC). The only significant associations with response propensity that remain are related to the firm characteristics of the employees, the size of the firm and, to a lesser extent, the sector of the firm. Large firms (more than 25 employees) are more likely than small firms to respond to the multi mode design (odds ratio greater than 3.0) while firms in the manufacturing, construction and transport, storage and communication sectors are less likely than firms in the public administration, defence and education sectors to be present in the sample obtained with the multimode design (odds ratio 0.20).

As suggested by the values of the goodness of fit, the two models are not able to describe fully the dynamics of the non-response in establishment surveys. The covariates examined here explain only a modest proportion of the variation in response propensity. Considering the importance of these variables for much analysis of business survey data, this is rather good news, suggesting that non-response error in key survey estimates may tend to be small in magnitude. The non-response seems rather to depend on some unobservable characteristics (such as perhaps the good will and time availability of the person/s who have to fill in the questionnaire).

\section{Data collection costs}

An assessment of the efficiency of the two survey designs requires also an evaluation of the data collection costs associated with each of them. In this section, we provide some limited information on the marginal costs of data collection associated with each survey design. ${ }^{4}$

In Table 7 we summarise our estimates of the costs of data collection. For the multimode survey design, the realised mean cost of data collection per respondent employer was $€ 21.4$. It would have been $€ 5.6$ if we had only carried out the postal survey. These figures exclude costs of data entry, data processing and researcher time, as we assume these to be independent of the mode of data collection.

\section{Conclusions}

As we stated in the introduction, many researchers are concerned with response rates and how to increase them. Multi mode data collection is gaining increasing recognition as a way of improving response rates, but little attention has been paid to the effects on non-response bias. And particularly in the context of establishment surveys, little has been reported regarding the effect of multi mode methods on non-response bias. In an establishment survey context

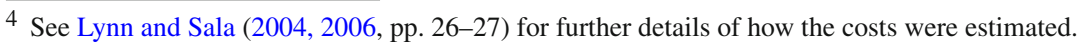


Table 7 Costs of data collection by mode of data collection

Note: The costs are expressed in Euro

\begin{tabular}{lclc}
\hline & $\begin{array}{l}\text { Postal } \\
\text { design }\end{array}$ & $\begin{array}{l}\text { Telephone } \\
\text { follow up }\end{array}$ & $\begin{array}{l}\text { Multimode } \\
\text { design }\end{array}$ \\
\hline Issued sample & 253 & 91 & 253 \\
Unit cost per issued & 2.8 & 34.6 & 15.3 \\
Respondent sample & 129 & 52 & 181 \\
Unit cost per respondent & 5.6 & 60.6 & 21.4 \\
\hline
\end{tabular}

we have found, in line with previous findings for household surveys (Gallagher et al. 2005) that improving response rates can also reduce non response bias. The efforts and the costs associated with the data collection process seem, therefore, to be worthwhile in terms of increasing the representativeness of the sample and reducing overall survey error. In our case study we found clear evidence of non-response bias in the first phase of the data collection. Bias was not evident with respect to the demographic characteristics of the employees, but it was associated with some of the employees' employment characteristics (occupation and managerial duties) and with firms' characteristics (industry classification and location of the firm). The telephone stage reduced or removed most of these biases, though some bias remained.

Overall, we can therefore conclude that the adoption of the multi mode data collection design was effective in reducing non-response bias in this case, especially the bias related to the employees' employment characteristics, though it did not remove bias completely. The reduction of the bias was not without cost. The unit cost of data collection per respondent employer increased from 5.6 euro for the postal survey to 21.4 euro for the multimode data collection. Survey designers have to be aware that the reduction of non response bias has very high costs. Such costs mainly depend on the type of multimode data collection design adopted.

This is, of course, not to say that multiple data collection modes used in sequence will always reduce non-response bias. Our objective in this article has been to demonstrate that at least in some circumstances multi mode designs can reduce bias and therefore that such designs have potential as a bias-reduction tool. As yet we have only limited information regarding the circumstances in which such approaches will be effective and regarding the optimum sequences of modes to use. Non-response bias will only be reduced if important characteristics of sample members who respond only in the second mode differ from those of sample members who respond in the first mode. This requires that the response mechanisms in the two modes are different, resulting in different types of sample members being more likely to respond in one mode than the other. In our case study, it may be for example that a portion of non-response to the postal survey was caused by mild concerns or uncertainty about confidentiality. In telephone mode, interviewers may have been able to allay those concerns and give sample members the confidence to respond. If propensity to have such concerns or uncertainty is correlated with key survey variables, then non-response bias reduction could result from the use of the second mode. In general, it may be the case that relative ability or motivation to respond in different modes varies across population segments. If this is correlated with key survey variables, a single mode survey may result in greater bias than a multi-mode survey.

We believe that multiple data collection modes used in sequence have the potential to reduce non-response bias. More research is needed to identify the nature of the response mechanisms in different modes and how these tend to correlate with common survey measures. 
In combination with knowledge about relative costs, this should help to identify optimum sequences of modes. More than two modes can of course be considered. Finally, this article has not addressed the issue of differential measurement error between modes. This, as well as costs and non-response bias, must be taken into account when choosing a multi mode survey design.

Acknowledgements This paper derives from the project, "Improving Survey Measurement of Income and Employment" (ISMIE), funded under the UK Economic and Social Research Council (ESRC) Research Methods Programme, grant number H333250031. We also benefit from the core funding of the UK Longitudinal Studies Centre (ULSC) at ISER, by the ESRC (award no. H562255004) and the University of Essex. We are grateful to our ISER colleagues for their assistance in running the employer survey described in this paper, especially Annette Jäckle, Heather Laurie and Fran Williams, and particularly to the two telephone interviewers, Joulie Gindi and Caroline McGrail. An earlier version of this paper was presented in the session, "Data Collection Process in Business Surveys," at the European Survey Research Association Conference in Barcelona, Spain, 18-22 July 2005. Emanuela Sala's attendance at the conference was supported by a British Academy Overseas Conference Grant.

\section{References}

Central Statistical Office: Standard Industrial Classification of Economic Activities 1992. HMSO, London (1992)

Cox, B.G., Binder, D.A., Chinnappa, B.N., Christianson, A., Colledge, M.J., Kott, P.S. (eds.): Business Survey Methods. John Wiley and Sons, New York (1995)

Curtin, R., Presser, S., Singer, E.: The effects of response rate changes on the Index of Consumer Sentiment. Public Opin. Q. 64, 413-428 (2000)

de Heer, W.: International response trends: results of an international survey. J. Off. Stat. 15(2), 129-142 (1999)

de Leeuw, E.D.: To mix or not to mix data collection modes in surveys. J. Off. Stat. 21(2), 233-255 (2005)

Dillman, D.A.: Mail and Internet Surveys: The Tailored Design Method, 2nd edn. John Wiley and Sons, New York (2000)

Dillman, D.A., Carley-Baxter, L.R.: Structural determinants of mail survey response rates over a 12-year period. In: Proceedings of the Survey Research Methods Section of the American Statistical Association 2000, pp. 394-399 (2000)

Employment Department Group and Office of Population Censuses and Surveys: Standard Occupational Classification, Volume 1: Structure and Definition of Major, Minor and Unit Groups. HMSO, London (1990)

Fisher, S., Bosley, J., Goldenberg, K., Mockovak, W., Tucker, C.: A qualitative study of nonresponse factors affecting BLS establishment surveys: results. In: Proceedings of the Survey Research Methods Section, American Statistical Association, pp. 679-684 (2003)

Fox, J., Fisher, S., Tucker, C., Sangster, R., Rho, C.: A qualitative approach to the study of BLS establishment survey nonresponse. In: Proceedings of the Survey Research Methods Section, American Statistical Association, pp. 1500-1505 (2003)

Gallagher, P.M., Fowler, F.J., Stringfellow, L.V.: The nature of nonsponse in a Medicaid survey: causes and consequences. J. Off. Stat. 21(1), 73-87 (2005)

Groves, R.M.: Nonresponse rates and nonresponse bias in household surveys. Public Opin. Q. 70(5), 646-675 (2006)

Haraldsen, G.: Identifying and reducing response burdens in internet business surveys. J. Off. Stat. 20(2), 393-410 (2004)

Jäckle, A., Lynn, P.: Dependent interviewing and seam effects in work history data. J. Off. Stat (in press)

Jäckle, A., Sala, E., Jenkins, S.P., Lynn, P.: Validation of survey data on income and employment: the ISMIE experience. ISER Working Paper, 2004-14. University of Essex, Colchester. http://www.iser.essex.ac.uk/ pubs/workpaps/pdf/2004-14.pdf (2004)

Jenkins, S.P., Cappellari, L., Lynn, P., Jäckle, A., Sala, E.: Patterns of consent: evidence from a general household survey. J. Roy. Stat. Soc. Ser. A (Stat. Soc.) 169(4), 701-722 (2006)

Jenkins, SP., Lynn, P., Jäckle, A., Sala, E. Feasibility of linking household survey and administrative record data: new evidence for Britain. Int. J. Social Res Methodol (in press) 
Kaplan, A.F., Whiter, G.D.: Incentives in a business survey: a study in improving response rates. In: Proceedings of the Survey Research Methods Section, American Statistical Association, pp. 1756-1761 (2002)

Keeter, S., Miller, C., Kohut, A., Groves, R.M., Presser, S.: Consequences of reducing nonresponse in a national telephone survey. Public Opin. Q. 64,125-148 (2000)

Luo, A. and White, G.D.: Exploring a new establishment survey incentive to improve response rates. In: Proceedings of the Survey Research Methods Section, American Statistical Association, pp. 3915-3918 (2005)

Lynn, P., Sala, E.: The contact and response process in business surveys: lessons from a multimode survey of employers in the UK, ISER Working Paper, 2004-12. University of Essex, Colchester. http://www.iser. essex.ac.uk/pubs/workpaps/pdf/2004-12.pdf (2004)

Lynn, P., Sala, E.: Measuring change in employment characteristics: the effects of dependent interviewing. Int. J. Public Opin. Res. 18(4), 500-509 (2009)

Lynn, P., Jäckle, A., Jenkins, S.P., Sala, E.: The effects of dependent interviewing on responses to questions on income sources. J. Off. Stat. 22(3), 357-384 (2006)

Lynn, P., Jäckle, A., Jenkins, S.P., Sala, E.: The impact of interviewing method on measurement error in panel survey measures of benefit receipt: evidence from a validation study, ISER Working Paper, 2004-28. University of Essex, Colchester. http://www.iser.essex.ac.uk/pubs/workpaps/pdf/2004-28.pdf (2004)

Paxson, M.C., Dillman, D.A., Tarnai, J.: Improving response to business mail surveys. In: Cox, B., et al. (eds.) Business Survey Methods. John Wiley and Sons, New York (1995)

Petroni, R., Sigman, R., Willimack, D., Cohen, S., Tucker, C.: Response rates and nonresponse in bls and census bureau establishment surveys. In: Proceedings of the Survey Research Methods Section, American Statistical Association, pp. 4159-4166 (2004)

Smith, P., Pont, M., Jones, T.: Developments in business survey methodology in the Office for National Statistics, 1994-2000, with discussion. J. Roy. Stat. Soc. Ser. D (Statistician) 52(3), 257-296 (2003)

Steeh, C., Kirgis, N., Cannon, B., DeWitt, J.: Are they really as bad as they seem? Nonresponse rates at the end of the twentieth century. J. Off. Stat. 17(2), 227-247 (2001)

Tarnai, J., Paxson, M.C.: Survey mode preferences of business respondents. In: Proceedings of the Survey Research Methods Section, American Statistical Association, pp. 4898-4904 (2004)

Willimack, D.K., Nichols, E., Sudman, S.: Understanding unit and item nonresponse in business surveys. In: Groves, R.M., et al. (eds.) Survey Nonresponse. John Wiley, New York (2002) 